\title{
Identification of the main dyestuffs obtained from Kermes (Kermes vermilio) in the Northwest of Turkey
}

\author{
Serap AYAZ SEYHAN, ${ }^{* 1}$ Cağlar DEMİRBAĞ ${ }^{2}$ and Emre DÖLEN ${ }^{1}$ \\ ${ }^{1}$ Marmara University, Faculty of Pharmacy Department of Analytical Chemistry, 34668, Istanbul, Turkey \\ ${ }^{2}$ Edirne University, Faculty of Pharmacy Department of Analytical Chemistry, 22030, Edirne, Turkey
}

\begin{abstract}
Dyer's kermes (Kermes vermilio) is found only on the kermes oak (Quercus coccifera L). They were used in the past for the preparation of dyes for textiles and as a pharmaceutical. The main constituents of this insect are kermesic acid $(k a)$ and flavokermesic acid $(f k)$. Historically and culturally important dyer's kermes insect red dyes were investigated by high performance liquid chromatography. Kermes in the Northwest of Turkey were analyzed first time the relative amount of the dyestuffs although their presence has been reported analytical works related to this insect. The relative amount in the acid hydrolyzed extract of Kermes vermilio from the Northwest of Turkey looked very similar to the France.
\end{abstract}

Keywords: flavokermesic acid, HPLC, kermesic acid, kermes insect, natural dyes.

\section{Introduction}

In ancient times, some insects were benefited from various regions of the world especially to obtain the red color. The among of many species of insects containing red dyes, who have gained importance: American cochineal (Dactylopius coccus), Polish cochineal or Polish kermes (Porphyrophora polonica), Ararat cochineal (Porphyrophora hamelii), kermes (Kermes vemilio) and lac insect (Kerria lacca). Kermes was used as the most expensive and the most valued red dye [1,2]. The insect that have been and are still used as sources of red textiles dyes, paint, pigment, food and pharmaceutical colorants. Kermes dye was prepared from a coccid insect species, Kermococcus vermilis Planchon (formerly Kermes ilicis L. or Kermes vermilio) (family called the Eriococcidae $=$ Kermidae). The insect producing this dye reproduces and feeds exclusively on the shrub oak Quercus coccifera (Kermes Oak). Kermes is found in the Mediterranean region of southern Europe and Turkey [1, 3]. Alum-mordanted kermes dyeing of wool and silk produces bright red hues. On wool, this red has a light-yellow tinge and thus approaches the warm color of the madder red. Kermes was known and has been used in Europe from Roman times, or even before. The most consequential red dye known to the ancient Mesopotamians was kermes ("girmis" in Arabic). It is acquired from the dried female insects which grow on the Mediterranean oak. Kermes lost its important significance in the dyeing industry soon after the Spaniards entered the market with the cochineal insect from the New World [4, 5].

Kermes was not only utilized by dyers but also for in ancient times the extract of kermes was utilized as medicine [2]. It was used in the treatment of wounds and eye congestion. Abu ben-Masouiach (the famous Arab physician) claimed kermes as a medicine to warn the heart, and it was used as a cardiac drug in Europe until the 18th century. F. Silvestri confirms that the most advised medicine during the 8th and 9th centuries was the extract of kermes (Alkermes) and he indicated that the color and the aroma of the liqueur have contributed to its effectiveness $[1,4,6]$.

The main constituent of this insect, kermesic acid $(\mathrm{ka})$ (CI 75460), which is the aglycone of carminic acid (cochineal), was isolated for the first time by R. Heise at the end of the 19th century. Its chemical structure, investigated by $\mathrm{O}$. Dimroth and co-workers, was established definitively in 1964 by J. C. Overeem and G. J. M. van der Kerk. Kermes also contains a small proportion of another yellow-orange anthraquinone colorant ( $3 \mathrm{~g}$ in $5 \mathrm{~kg}$ of insects), the flavokermesic acid (fk) $[1,7]$. Verhecken and Wouters have shown that it is in fact laccaic acid D [8]. These scientists have also revealed the presence of eight other colorants, as yet unidentified and the relative abundances in the acid hydrolyzed extract were: $15 \% \mathrm{fk}$ and $85 \% \mathrm{ka}$ (Yugoslavia), $18 \% \mathrm{fk}$ and $82 \% \mathrm{ka}$ (Spain), $20 \% \mathrm{fk}$ and $80 \% \mathrm{ka}$ (North-Africa), $27 \% \mathrm{fk}$ and $73 \% \mathrm{ka}$ (France) [9 - 11].

Historical objects are mostly dyed derived from different dye sources with mixtures of natural dyes. Also, these dye sources generally consist of a mixture of closely related compounds. The precise composition and ratio of these compounds can be used for identifying the specific dye source. High-performance liquid chromatography (HPLC) yields information about dyestuff composition. However, it is not to have access to standards for some of the compounds separated chromatographically. For this reason, the relative composition of dyestuff compounds is used as a rule for the identification of insect dye source. The relative composition $(\%)$ is calculated based on the correlation between peak area (or height) of each dyestuff and the total peak area (or height).

In this paper is presented an analysis of the composition of the dyestuffs from kermes (Kermes

\footnotetext{
* Corresponding author. E-mail address: serapayz@gmail.com (Serap Ayaz Seyhan)
} 
vermilio) in the Northwest of Turkey (Çanakkale). Although the main coloring components $(f k, k a$, and $k v I$ structurally unknown pigment of Kermes vermilio) from kermes have been characterized, the structures of some minor components remain unknown. For this reason, we presented the relative abundance of three dyestuffs. This method of dye analysis may improve the knowledge of ancient dyeing procedures and may contribute to Scale insect chemotaxonomy [10, 12].

\section{Experimental}

\subsection{Reagents and materials}

Adult female kermes insects (Kermes vermilio) were collected in Canakkale (the Northwest of Turkey) during June and July. All chemicals and solvents were reagent or HPLC grade. Kermesic acid and flavokermesic acid were obtained from INCO CT 2005015406 MEDCOLOUR-TECH of the project. The other chemicals and organic solvents were purchased from Merck (Darmstadt, Germany). Bidistilled deionized water was Milli-Q quality. The stock solutions of $k a$ and $f k$ were prepared daily.

\subsection{Sample preparation}

The kermes insects were washed over a griddle to eliminate dust and foreign materials. The insects were then dried at room temperature. Dried insects were ground in a ceramic mortar, and in the amber straight sided jar, $0.5 \mathrm{~g}$ of the powdered insect samples were mixed with $10 \mathrm{ml}$ of methanol/water $(9 / 1, \mathrm{v} / \mathrm{v})$. The mixture was homogenized in orbital shaker (IKA) for 20 min, and the sample was extracted at $27^{\circ} \mathrm{C}$ with shaking water bath. After 24 hours, the recovery of all dyestuffs considered reached completion in this extracting condition $[9,10]$. The extracts were centrifuged at 3600 rpm for 3 minutes. The supernatant was used for the determination of dyestuffs.

The composition of an acid hydrolysate was: extract/methanol/37\% $\mathrm{HCl}(1 / 1 / 2$, v/v/v). Heating was performed at $100{ }^{\circ} \mathrm{C}$ for $10 \mathrm{~min}$ in boiling tubes. The extracts were dried under $\mathrm{N}_{2}$ and were re-dissolved in water/methanol $(1 / 1, \mathrm{v} / \mathrm{v})[9,10]$. The extracts were stored in glass vials at $-20{ }^{\circ} \mathrm{C}$ in darkness until chromatographic analysis. The extract filtered through a $0.45 \mu \mathrm{m}$ nylon filter (Biocrom MN 718020, Phonex nylon filter $25 \mathrm{~mm}$ ) prior to injection into the HPLC system.

\subsection{Chromatographic conditions}

All extracts were analyzed on a HPLC-DAD system (Agilent Technologies, High Performance Liquid Chromatography was a combination of a Model G1311A quaternary pump, a Model G1322A vacuum degasser and a Model G1315A diode array detector, series 1200 autosampler). The separation was performed on Phenomenex, Luna, $5 \mu \mathrm{m}$, C18 ODS-RP 250 x $4.6 \mathrm{~mm}$ column. The column temperature was $30{ }^{\circ} \mathrm{C}$. The mobil phase consisted of $\mathrm{A}$ (orthophosphoric acid $0.05 \%$ in water) and $\mathrm{B}$ (methanol). Gradient elution conditions were: $0-1 \min 25 \% \mathrm{~B}, 1-7 \mathrm{~min}$ from $25 \%$ to $50 \% \mathrm{~B}, 7-23$ min from $50 \%$ to $70 \% \mathrm{~B}, 23-30 \mathrm{~min}$ from $70 \%$ to $50 \% \mathrm{~B}$, $30-35$ min from $50 \%$ to $25 \% \mathrm{~B}$, and $35-40$ min $25 \% \mathrm{~B}$. Flow rate was $0.8 \mathrm{ml} / \mathrm{min}$ and injected volume $20 \mu \mathrm{l}$. The $k a$ and $f k$ were detected at $275 \mathrm{~nm}$. $k a$ and $f k$ stock solutions were prepared in methanol/water (1/1) and stored at $4{ }^{\circ} \mathrm{C}$ in darkness.

It is not to have achieved to standards for some of the compounds separated chromatographically in the analysis of natural dyes. The relative composition of this component is used as a rule for the identification of a kermes insect source: $k v I, k a$ and $f k$.

\section{Results and discussion}

\subsection{Chromatographic determination of dyestuffs}

Initially, the chromatographic conditions defined by Wouters and Verhecken [10] were pursued to separate the pigments. Then different solvent mixtures (methanol/water, acetonitrile/water, methanol/water/ orthophosphoric acid) and gradient programs were used $[13,14]$. The results were better obtained using a mixture of orthophosphoric acid ( $0.05 \%$ in water) and methanol. Detection wavelengths were set at $275 \mathrm{~nm}$ and $420 \mathrm{~nm}$ (yellow pigments) and $500 \mathrm{~nm}$ (red pigments) at the same time. The spectra (from 200 to $700 \mathrm{~nm}$ ) were recorded for all peaks. To define components separated by chromatography, a wavelength of $275 \mathrm{~nm}$ seems adequate [14]. Identification of $k a$ and $f k$ was carried out by comparing retention times and their visible spectral data with those of standards (Fig. 1).

Considering that mobile phase prepared in low $\mathrm{pH}$ value would be effective in the peak separation and peak form correction. The $K$. vermilio dyestuffs were separated under the optimal HPLC conditions as demonstrated in Figs. 2 and 3. Samples were injected in duplicate.

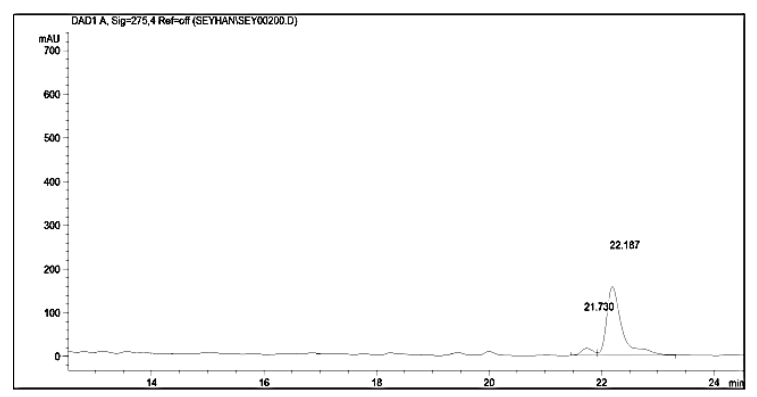

Figure 1. Chromatogram of the standard dyestuff mixture at $275 \mathrm{~nm}$. flavokermesic acid, Rt:21.73; kermesic acid, Rt:22.18.

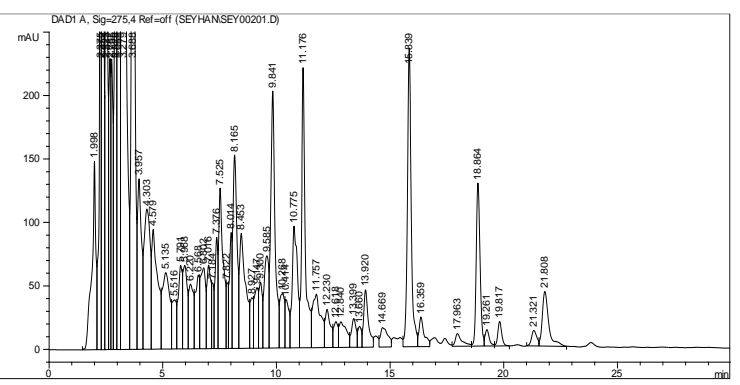

Figure 2. Chromatographic separation of an aqueous extract of $K$. vermilio by HPLC with UV-visible detection at $275 \mathrm{~nm}$. $K$. vermilio pigments: minor dyestuffs are designated yellow and red, flavokermesic acid, Rt:21.32; kermesic acid, Rt:21.80; $k v I$, Rt:15.83.

Detection wavelengths were set at $275 \mathrm{~nm}$. The identities of the different chromatographic peaks were 
verified by comparing their visible spectral characteristics with retention times and the standard of $k a$ and $f k$ (Fig. 4) and by using the information previously reported in the literature $[9,10]$.

The spectra of the other kermes insect pigments were compared with the results published by Wouters and Verhecken [10]. Results were expressed as relative amount that based on peak area.

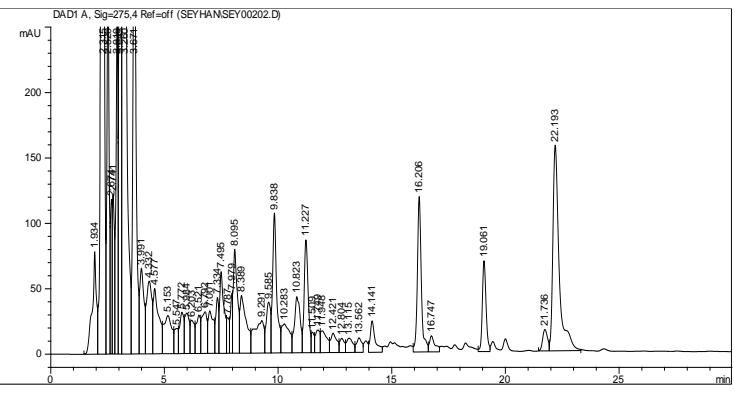

Figure 3. Chromatographic separation of $K$. vermilio hydrolyzed extract by HPLC with UV-visible detection at 275 $\mathrm{nm}$. K. vermilio pigments: minor dyestuffs are designated yellow and red, flavokermesic acid, Rt:21.73, and kermesic acid, Rt:22.19.

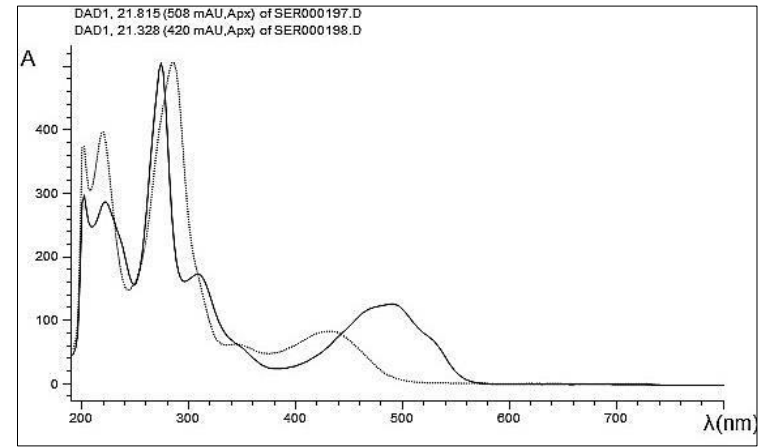

Figure 4. UV-vis spectra of the standard of flavokermesic acid $(. . . .$.$) and kermesic acid \left(\_\right)(420 \mathrm{~nm}$ and $500 \mathrm{~nm})$

In kermes insect extracts were found many dyestuffs both reds and yellows. The most important of these were specified $k v I, f k$ and $k a$. Carminic acid or any other dyestuff (e.g. $d c I V, d c V I I)$ were not found at all. $k v I$ was acid labile precursor of $f k$ and $k a$ [9]. In the extract of $K$. vermilio, three dyestuff peaks are obvious: $k v I, f k$ and $k a$. Minor reds and yellows were also present. Acid hydrolysis decreased $k v I$ and at the same time, $f k$ and $k a$ were increased. The dyestuff composition of $K$. vermilio (adult female) and the correlation between $k v I, f k$ and $k a$ is given in Table 1. The relative abundances in the acid hydrolyzed extract were: $30 \% \mathrm{fk}$ and $70 \% \mathrm{ka}$ (NorthwestTurkey).

Table 1. The relative abundance of the dyestuff of $K$. vermilio $(n=6)$

\begin{tabular}{cccc}
\hline $\begin{array}{c}\text { Kermes } \\
\text { vermilio }\end{array}$ & $\% k v I$ & $\% f k$ & $\% k a$ \\
\hline $\begin{array}{c}\text { Extraction } \\
\text { Acid }\end{array}$ & $65 \pm 0.11$ & $05 \pm 0.11$ & $30 \pm 0.11$ \\
hydrolysate & - & $30 \pm 0.15$ & $70 \pm 0.15$
\end{tabular}

All experiments were performed with specimens gathered in the Northwest of Turkey. Results were expressed as relative abundance that based on peak area. The dyestuffs found in the $K$. vermilio can be efficiently extracted using an adequate selection of the experimental conditions optimized in this study. The chromatographic conditions defined by Wouters and Verhecken [10] were pursued to separate the pigments. Then different solvent mixtures (methanol/water, acetonitrile/water, methanol/ water/orthophosphoric acid) and gradient programs were used $[13,14]$. The results were better obtained using a mixture of orthophosphoric acid $(0.05 \%$ in water) and methanol.

\section{Acknowledgments}

Kermesic acid and flavokermesic acid were provided by INCO CT 2005015406 MED-COLOUR-TECH project. Kermes vermilio was provided by Prof. Dr. Recep Karadağ. This work was supported by Marmara University Scientific Research Unit as SAG-D-1109130372 numbered project.

\section{Conflict of interest}

The authors confirm that this article content has no conflicts of interest.

\section{References}

[1]. D. Cardon, Natural dyes sources, tradition, technology and science, Archetype Publications Ltd., London, pp. 607-710 (2007).

[2]. E. Dölen, Textile history - The historical development of the textile industry and technology in the world and Turkey (it is written in Turkish), M.Ü. Technical Education Faculty Publications No: 92/1, İstanbul, (1992) 457-537.

[3]. H. Böhmer, N. Enez, R. Karadağ, C. Kwon, Koekboya: Natural dyes and textiles, Garderkesee, Germany, pp. 203-206 (2002).

[4]. H. Schweppe, H. Roosen Runge, CarmineCochineal carmine and Kermes carmine. In: Artists' Pigments: A Handbook of Their History and Characteristics, vol: 1, Robert L. Feller ed., National Gallery of Art, Washington, pp. 255-283 (1987).

[5]. P. Mushak, The use of insect dyes in oriental rugs and textiles: some unresolved issues, Oriental Rug Review: A Bimonthly Journal of Oriental Rugs and Other Textiles 8 (1988) 33-39.

[6]. R.I. McCallum, Section of occupational medicine, Proc. Roy. Soc. Med. 70 (1977) 756-763.

[7]. A.G. Perkin, A.E. Everest, The natural organic colouring matters, Longmans, Green and Co., London (1918).

[8]. J. Wouters, A. Verhecken, The chemical nature of flavokermesic acid, Tetrahedron Lett. 28 (1987) 1199-1202.

[9]. J. Wouters, A. Verhecken, The coccid insect dyes: HPLC and computerized diode - array analysis of dyed yarns, Stud. Conserv. 34 (1989) 189-200.

[10]. J. Wouters, A. Verhecken, The scale insect dyes (Homoptera: Coccoidea). Species recognition by HPLC and diode-array analysis of dyestuffs, Ann. Soc. Entomol. Fr. (N.S). 25 (1989) 393-410.

[11]. J. Wouters, High performance liquid chromatography of anthraquinones: analysis of 
plant and insect extracts and dyed textiles, Stud. Conserv. 30 (1985) 119-128.

[12]. J. Wouters, Dyestuff analysis of scale insects by high performance liquid chromatography (Homoptera: Coccoidea), Proc. ISSIS - VI, Krakow, (1990) part II 61-70.

[13]. J. Wouters, N. Rosario-Chirinos, Dye analysis of pre-columbian peruvian textiles with highperformance liquid chromatography and diodearray detection, JAIC 31 (1992) 237-255.
[14]. M. Gonzalez, J. Mendez, A. Carnero, M.G. Lobo, A. Afonso, Optimizing conditions for the extraction of pigments in cochineals (Dactylopius coccus Costa) using response surface methodology, J. Agric. Food Chem. 50 (2002) 6968-6974.

Received: 15.10 .2018

Received in revised form: 14.01.2019

Accepted: 17.01.2019 